\title{
Leaching Characteristic of Arsenic in Coal Fly Ash
}

\author{
Sri Hartuti, Shinji Kambara, Akihiro Takeyama and Farrah Fadhillah Hanum \\ Faculty of Engineering, Gifu University, Gifu 501-1193, Japan
}

\begin{abstract}
The leaching characteristics of arsenic from six CFA (coal fly ash) samples collected from a large scale power plant in Japan were investigated to evaluate more fully the rate of leaching of arsenic and related factors on determining arsenic leaching from different type of CFAs. The procedure of standard leaching tests according to Environmental Agency of Japan Notifications No. 13 was employed in this work. The results indicate that the leaching fractions of arsenic were low levels below $15 \%$, and it was affected by $\mathrm{CaO}$ content in CFA. Leaching test results were compared with solution equilibrium calculation to consider the leaching mechanisms: however, experimental results were significantly lower than the equilibrium calculation results. To elucidate the leaching mechanisms, the leaching rate was investigated by extending the leaching tests for a long-term. The concentration of arsenic in the leachate was increased with time, and equilibrium between the solid phase (ash) and the leaching solution was reached in approximately 120 days. It is found that the constant $a$ has a good relationship with CaO content in CFAs, in which the constant $a$ (indicated leaching rate of arsenic) was decreased with an increase of $\mathrm{CaO}$ content in fly ash. Therefore, the value of the rate constant $a$ can be said to be the main factor determining arsenic leaching.
\end{abstract}

Key words: Coal fly ash, arsenic, leaching rate, equilibrium calculation.

\section{Introduction}

The discharge of fly ash from coal combustion process has become the matter of concern over last few decades. Coal which is contained significant quantities of many hazardous trace elements burned in boiler of coal-fired power plant to generate electricity. After burning, as the flue gas cools down, trace elements such as As, B, Cr and Se condensed on the surface of the fly ash (collected by electrostatic precipitators) and formed new stable compounds [1]. The collected CFAs (coal fly ashes) by electrostatic precipitators are usually subjected to be reused or disposed. The fly ash is reused as substitute material for Portland cement, structural fills (usually for road construction), soil stabilization, mineral filler in asphaltic concrete, and mine reclamation has been well recognized [2], but most of the fly ash generated from the power plants such as CFAs having large amount of unburned carbon which are unsuitable as the raw material for cement will be disposed to the

Corresponding author: Shinji Kambara, Ph.D., professor of materials chemistry, research fields: pulverized coal, trace elements. landfill. This disposal gives negative impact to the environment, where due to the rainfall the trace elements contained in fly ash will be eluted to the environment [3].

Arsenic, one of the most highly toxic chemicals, is a semi-metallic element commonly found as arsenite and arsenate compounds [4]. The leaching of arsenic from fly ash will contaminate the aquifer systems, and raise the water-environmental problem. It has been described on previous studies that $\mathrm{pH}, \mathrm{S} / \mathrm{L}$ (solid-to-liquid) ratios, leaching time, ash properties (e.g. acidic or alkaline) and the leaching environment are the factors which affect the leaching behavior of arsenic [5-11]. Wang et al. [12] investigated the effect of $\mathrm{pH}, \mathrm{S} / \mathrm{L}$ ratio, calcium addition and leaching time on the leaching behavior of As and Se from two major types of CFAs and they found that leaching of As and Se from CFA generally increased with increases in the $\mathrm{S} / \mathrm{L}$ ratio and leaching time, and adsorption/desorption played a major role in As and Se leaching from CFA. Jiao et al. [13] studied the leaching characteristics of As in fly ash and they found that the presence of $\mathrm{Ca}$ in fly ash plays an important role in the leaching 
behavior of As, where abundance of free $\mathrm{CaO}$ in fly ash generates an alkaline leachate during leaching test and successively reduces arsenic leaching since the precipitate was preferentially occurred via the reaction of arsenic with calcium at high $\mathrm{pH}$ leachate. Jankowski et al. [8] performed a long term leaching test for four Australian fly ashes and found that As leaching from both acidic and alkaline ashes was increased with time, after reaching a maximum concentration, As leaching from alkaline ash was decreased.

In this work, leaching characteristic of arsenic in six different CFA samples was investigated. The samples were collected from a commercial power plant for the leaching experiments. Solution equilibrium calculation was employed to clear the leaching mechanism of arsenic in fly ash, and the calculation results were compared with the experimental results. The influence of time was investigated through a long term leaching test and the effect of leaching rate on the leaching behavior of arsenic was discussed. The overall object of the study was to evaluate more fully the rate of leaching of arsenic and related factors on determining arsenic leaching from different type of CFAs, as a basis for comprehensive assessment of arsenic behavior. The leaching mechanism and the rate of leaching of arsenic were monitored as a basis for finding out the principle of leaching suppression method to prevent the leaching of arsenic. This type of information is different from that produced by simple and standardized leaching tests in which this study involves a long-term leaching process for CFAs, but it is necessary for a more confident approach to aid in the development of sustainable fly ash management strategies.

The novelty of the paper lies in the application of long leaching time of 120 days and observation of leachates during 4 periods to obtain detailed time-series changes in leaching fraction of leachate solutions for monitoring the rate of leaching of arsenic.

\section{Materials and Methods}

\subsection{CFA Samples}

Six CFA samples (G, H, I, J, L, and N) were collected from a pulverized coal fired power plant. Fly ashes $\mathrm{H}$ and $\mathrm{I}$ derived from the same coal between unit 1 and 2 of coal fired power plants. Table 1 shows the major chemical compositions that were measured by XRF (X-ray fluorescence). Trace element arsenic was measured by ICP-AES. It should be noted that the concentration ranges of As have wide ranges in six CFA samples as shown in Table 1.

\subsection{Characterization of Elements in CFA Samples}

Total concentrations of major chemical compositions were determined using Wavelength Dispersive X-ray Fluorescence Spectrometer (WDXRF S8 TIGER, Bruker AXS). For XRF analysis of CFA samples, a few amount of it (approximately $500 \mathrm{mg}$ ) was poured on polypropylene thin-film which was attached previously onto a Plastic-made O-ring sample cup with an outer diameter of $40 \mathrm{~mm}$. The samples were introduced to XRF instrument, and the chemical compositions of samples were determined.

The concentration of arsenic in CFA was determined using microwave-assisted acid-digestion followed by HG-ICP AES (hydride generation-inductively coupled plasma atomic emission spectrometry) analysis. Sample digestion was carried out in a microwave oven (MDS 2000) fitted with an exhaust unit and a microprocessor to control the power and thermal program. About $0.1 \mathrm{~g}$ ash sample was weighted and moved into a pressureresistant PTFE (Polytetrafluoroethylene) bottle. An acid mixture capable of completely digesting ash sample was $2 \mathrm{~mL}$ of $\mathrm{HNO}_{3} 65 \%$, and $4 \mathrm{~mL}$ of $\mathrm{HF}$ $50 \%$ was added, the bottle was then sealed and a digestion program was performed. After cooling and the addition of $5 \mathrm{~mL}$ of saturated $\mathrm{H}_{3} \mathrm{BO}_{3}$, microwave processing was performed again. Boric acid was added after dissolution to neutralize the corrosive hydrofluoric. 
Table 1 Chemical composition of CFA samples.

\begin{tabular}{|c|c|c|c|c|c|c|c|}
\hline Fly ash samples & & G & $\mathrm{H}$ & I & $\mathrm{J}$ & $\mathrm{L}$ & $\mathrm{N}$ \\
\hline Power plant & & Unit 2 & Unit 1 & Unit 2 & Unit 2 & Unit 2 & Unit 2 \\
\hline $\mathrm{SiO}_{2}$ & \multirow{12}{*}[\%]{} & 62.45 & 59.25 & 59.00 & 65.38 & 58.09 & 62.98 \\
\hline $\mathrm{Al}_{2} \mathrm{O}_{3}$ & & 26.48 & 25.63 & 25.97 & 21.60 & 21.36 & 23.20 \\
\hline $\mathrm{TiO}_{2}$ & & 1.74 & 1.99 & 1.86 & 1.06 & 0.89 & 1.20 \\
\hline $\mathrm{Fe}_{2} \mathrm{O}_{3}$ & & 3.18 & 7.49 & 7.25 & 7.14 & 6.40 & 5.33 \\
\hline $\mathrm{CaO}$ & & 0.93 & 2.05 & 2.09 & 1.43 & 8.24 & 2.59 \\
\hline $\mathrm{MgO}$ & & 0.54 & 0.79 & 0.86 & 0.52 & 1.07 & 1.16 \\
\hline $\mathrm{Na}_{2} \mathrm{O}$ & & 0.28 & 0.60 & 0.65 & 0.43 & 0.83 & 1.36 \\
\hline $\mathrm{K}_{2} \mathrm{O}$ & & 0.56 & 1.56 & 1.50 & 1.77 & 1.86 & 1.41 \\
\hline $\mathrm{P}_{2} \mathrm{O}_{5}$ & & 0.07 & 0.18 & 0.17 & 0.16 & 0.27 & 0.19 \\
\hline $\mathrm{MnO}$ & & 0.11 & - & 0.10 & - & - & - \\
\hline $\mathrm{V}_{2} \mathrm{O} 5$ & & 0.02 & 0.03 & 0.04 & 0.15 & 0.15 & 0.04 \\
\hline $\mathrm{SO}_{3}$ & & 0.64 & 0.42 & 0.51 & 0.38 & 0.84 & 0.54 \\
\hline As in fly ash & {$[\mathrm{mg} / \mathrm{kg}]$} & 4.53 & 35.01 & 43.94 & 14.92 & 11.71 & 23.68 \\
\hline As leaching amount & {$[\mu \mathrm{g} / \mathrm{L}]$} & 61.75 & 122.8 & 112.5 & 49.8 & 2.00 & 63 \\
\hline
\end{tabular}

After cooling, the residue was dissolved and diluted to $50 \mathrm{~mL}$ using $\mathrm{HCl} 10 \%$ and $\mathrm{KI} 20 \%$.

\subsection{Leaching Tests}

The procedure of standard leaching tests for fly ashes Notification No. 13 by the Environmental Agency of Japan was basically employed as the leaching tests in this work. However, in this way, variation in $\mathrm{pH}$ of leachate during leaching tests strongly affects leaching concentration of elements, so a buffer solution $(\mathrm{pH}=10)$ was used as a leaching solution, which can keep a constant $\mathrm{pH}$ around 10 .

Regarding the leaching procedure used in this work, fly ash of $50 \mathrm{~g}$ and $500 \mathrm{~mL}$ buffer solution $(\mathrm{pH}=10)$, which accounted for a liquid to solid ratio (L/S) of 10 , were mixed in a polyethylene bottle, after then, it was shaken for 6 hours at room temperature with a shaking speed of 200 r.p.m. The solid-liquid sample was separated by a filtration using a membrane filter of $0.45 \mu \mathrm{m}$ to obtain the filtrate. The concentration of arsenic in filtrate was carefully analyzed by HG-ICP AES (ULTIMA2, HORIBA Ltd).

Extended leaching time (long term leaching) has been carried out to elucidate effects of time on the leaching of As. The leaching time was continued for 120 days, in which every 30 days, the concentration of arsenic in the leachate was observed. The value of leaching fraction refers to the percentage of mass of arsenic in leachate to its mass in fly ash.

\subsection{Thermodynamic Equilibrium Calculation}

To consider the leaching fraction of arsenic theoretically in the case of solution equilibrium, the thermodynamic equilibrium software, FactSage 6.0 was used. It has optimized databases for solutions of metals, liquid, and solid, which can be applied for equilibrium calculation in the liquid-solid system. In the equilibrium calculation, chemical composition as shown in Table 1 and liquid conditions $\left(25^{\circ} \mathrm{C}\right.$, of 1 atm) were set on FactSage 6.0 as calculation input. The databases used include Fact 53 and FTmisc, and solid species is chosen as an output.

\section{Results}

\subsection{Leaching Characteristics}

Fig. 1 shows the leaching fraction of arsenic for six CFA samples. The fraction ranges from 0 to $15 \%$. This low value of leaching fraction exhibits relatively weak relationship between the leaching amount of arsenic and its element concentration in fly ash. As shown in Fig. 2, the correlation coefficients $\left(R^{2}\right)$ between 


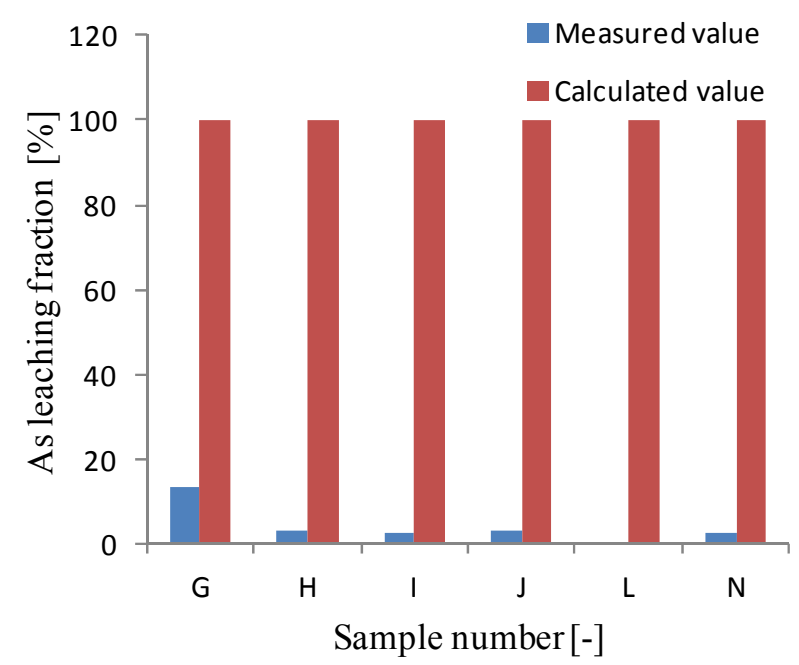

Fig. 1 Leaching fractions of arsenic for 6 CFA samples: left bar is experimental result, and right bar is equilibrium calculation.

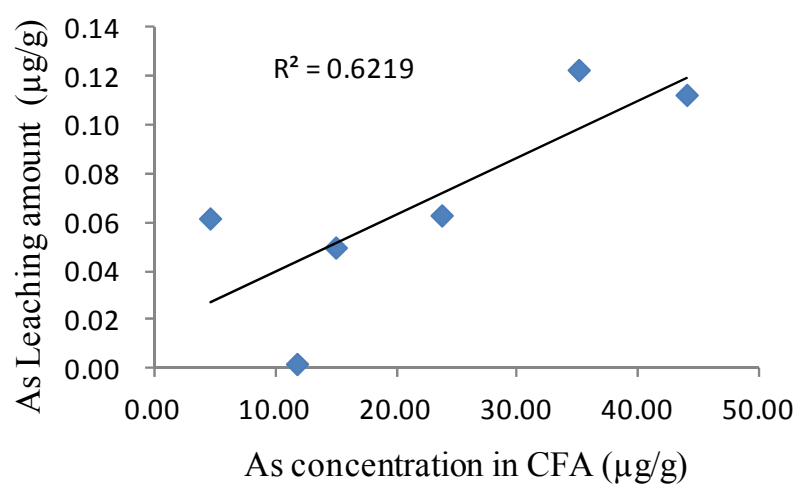

Fig. 2 Relationship between leaching amounts and concentration of arsenic in CFAs.

leaching amount of arsenic versus its concentration in the solid phase is 0.62 .

Sample $\mathrm{L}$ has the highest amount of $\mathrm{CaO}$ content (Table 1) of all six CFAs tested, and the lowest leaching fraction of $0 \%$, on the other hand, sample $\mathrm{G}$ has the lowest amount of calcium, and the highest leaching fraction of $15 \%$. A plausible process responsible to the release of arsenic from fly ash $\mathrm{L}$ would be high content of $\mathrm{CaO}$ in fly ash $\mathrm{L}$ preferentially associating with arsenic to form solid stable compound of $\mathrm{Ca}_{3}\left(\mathrm{AsO}_{4}\right)_{2}$ and the formation of insoluble $\mathrm{Ca}_{3}\left(\mathrm{AsO}_{4}\right)_{2}$ can lead to a decrease in the dissolved arsenic concentration in the leachate $[8$, 13-16].

\subsection{Comparison with Equilibrium Calculation Results}

To consider the leaching mechanisms of arsenic, solution equilibrium calculation was performed by FactSage 6.0. In the calculation, the parameter survey has been carefully carried out, and the leaching time was assumed as infinite time. The effect of temperatures of the solution and value of $\mathrm{pH}$ on the leaching fractions was negligible. As can be seen in Fig. 1, the calculation results show that the leaching fraction of arsenic was $100 \%$ for all fly ash samples, and these values were significantly different from experimental results value. This discrepancy may depend upon the leaching time because the leaching time has been assumed as infinite time in the equilibrium calculation. This observation indicates that arsenic leaching is time-dependent.

\subsection{Long-Term Leaching Characteristic}

As mentioned in the discussion above, the leaching time is one of the important factors in arsenic leaching mechanism. To investigate the effect of the leaching time, the long-term leaching test was conducted. Fig. 3 shows plot of changes in the leaching fractions of arsenic for 3 CFAs (H, I, and L) at 30th, 60th, 90th and 120th day leaching time. As expected, the leaching fractions were increased with the leaching time for all samples.

As shown in Fig 3, the leaching fractions of sample $\mathrm{H}$ and I were much higher than that of the sample $\mathrm{L}$ for all terms, and most of arsenic in CFA was eluted at 120th day for the sample $H$ and I. Leaching fraction of sample I reached $100 \%$ at 120 th day $(2.6 \%$ at short-term leaching test, see Fig. 1). In addition, although fly ashes $\mathrm{H}$ and I were derived from the same coal of different unit in power plants, they have different arsenic leaching fraction on the 120th day, and fly ash $\mathrm{H}$ has a slightly lower leaching fraction than fly ash I. Fly ash L indicated $0 \%$ leaching fraction through short-term leaching test as can be seen in Fig. 1, but the leaching fraction was reached about $50 \%$ through long-term leaching test as can be 
seen in Fig. 3. It is predicted that the leaching fraction of the sample L will be reached $100 \%$ in longer day.

Therefore, the results of equilibrium calculations give correct suggestions with this long-term leaching experiment result that the total amount of arsenic will be eluted at the end, and the equilibrium between the solid phase (ash) and the leaching solution was reached in this long-term leaching experiments. This observation is opposite to that reported by Jankowski, who found that the equilibrium between the solid phase (ash) and the leaching solution was not reached in 144 hours (6 days) leaching experiments [8, 17, 18]. It was concluded that longer leaching test may be responsible for this observation, where the diffusion process of arsenic from the inner pores of fly ash to the surface and bulk solution might be resulted from a slow process through a longer term release [12, 19]. From the results shown in Fig. 3, it is clear that a leaching rate is an appropriate factor to evaluate leaching characteristics of arsenic for various types of CFAs.

\subsection{Evaluation of Leaching Rates of Arsenic}

As can be seen in Fig. 3 that leaching fraction of arsenic varies depending on coal type, here we calculate the arsenic leaching rate of fly ash $\mathrm{H}, \mathrm{I}$ and $\mathrm{L}$ to investigate the behavior of leaching fraction shown in Fig. 3. The leaching rate was expressed based on kinetic model of first-order reactions [20], and the rate equation was defined as follows:

$$
X=1-\exp (-k . t)
$$

where, $X[-]$ is the leaching fraction of arsenic; $k$ is the rate constant and $t$ is time. By Eq. (1), the change in arsenic leaching fraction can be represented freely by changing the rate constant $k$, but since the leaching fraction of arsenic varies depending on coal type, the behavior of leaching fraction becomes complex, it is required to modify the equation to express the leaching fraction profile for each coal type, the modified equation was defined as follows:

$$
X=1-\exp \left(-a . t^{b}\right)
$$

where, $X[-]$ is the leaching fraction of arsenic, and constant $a$ and $b$ were variables to express the complex behaviors of leaching fractions for a long-term. The constant $a$ and $b$ are estimated by data fitting to Eq. (2). Fig. 4 shows the results of data fitting, and constant $a$ and $b$ are indicated in Table 2 . As can be seen in Fig. 4, the solid line indicates the result of the modified leaching rate in Eq. (2), the trend of the leaching rate equation as a calculation result shows a good agreement with the behavior of leaching fraction as an experimental results.

The constants $a$ and $b$ as a variable to express the complex behaviors of long-term leaching fractions are defined to observe the transition of As leaching fraction through locking the value of one constant such as constant $b$ and varying the other constant value such as constant $a$. Fig. 5 shows the As leaching

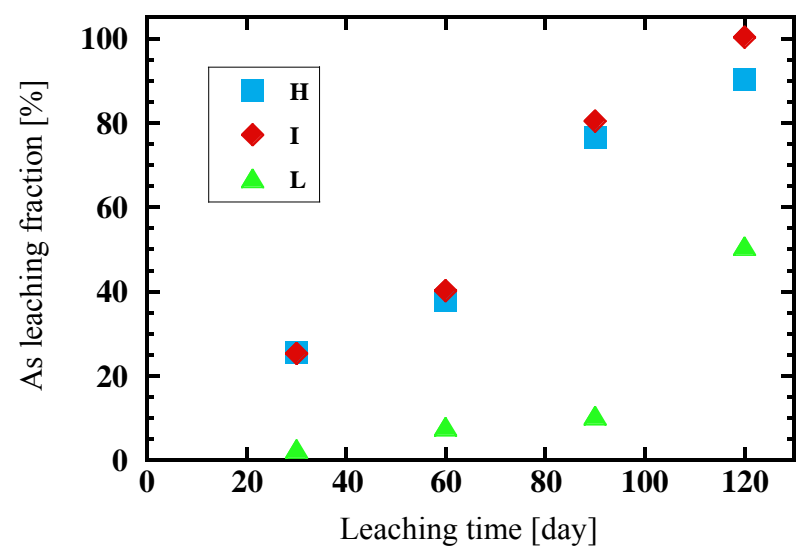

Fig. 3 Effect of leaching time on as leaching fraction.

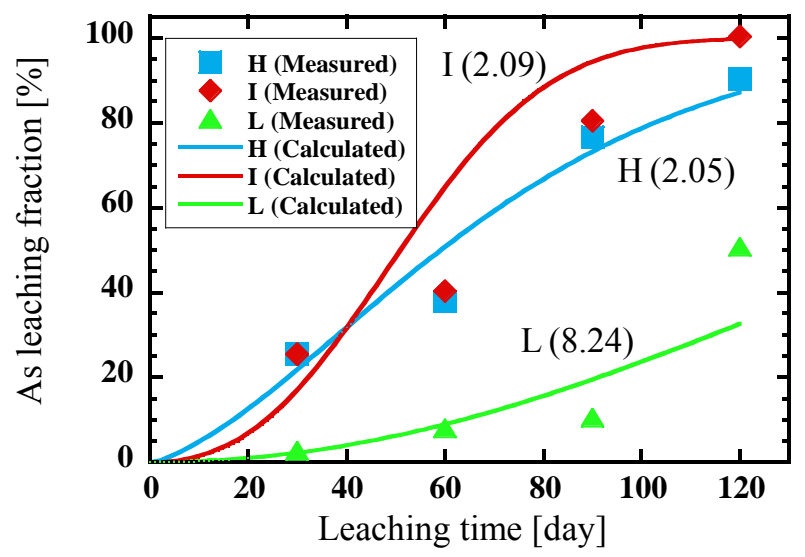

Fig. 4 Fitting results by Eq. (2) for three different CFAs. The value in parentheses is $\mathrm{CaO} \%$ in the CFA. 
Table 2 List of constant $a$ and $b$ for 6 different CFAs.

\begin{tabular}{lllllll}
\hline & $\mathrm{G}$ & $\mathrm{H}$ & $\mathrm{I}$ & $\mathrm{J}$ & $\mathrm{L}$ & $\mathrm{N}$ \\
\hline$a$ & 0.2429 & 0.1627 & 0.1049 & 0.2461 & 0.0043 & 0.1521 \\
$b$ & 0.3429 & 0.4164 & 0.7073 & 0.2583 & 0.6696 & 0.2553 \\
\hline
\end{tabular}

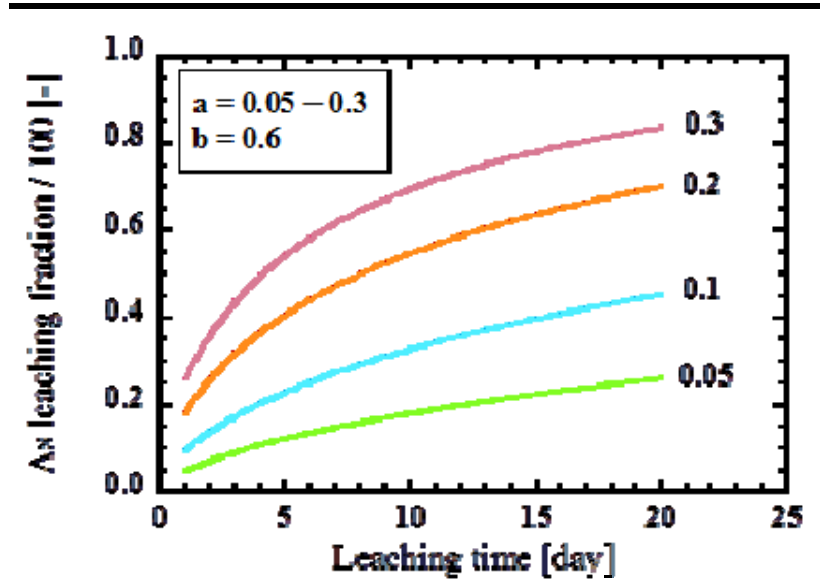

Fig. 5 Effect of constant "a" on As leaching fraction and leaching rate equation. The change in As leaching fraction when " $a$ " is changed and " $b$ " is kept constant.

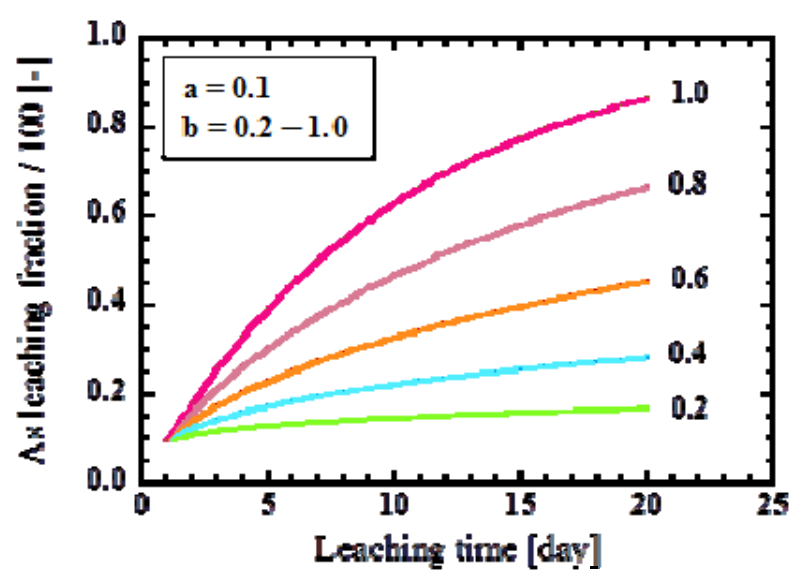

Fig. 6 Effect of constant " $b$ " on As leaching fraction and leaching rate equation. The change in As leaching fraction when " $b$ " is changed and " $a$ " is kept constant.

fraction by changing the $a$ is fixed to $b$, and Fig. 6 shows the As leaching fraction by changing the $b$ is fixed to $a$. As can be seen in Fig. 5, initial As leaching fraction increases with increasing $a$. On the other hand, there is no change in the initial As leaching fraction in Fig. 6, but the leaching rate increases with increasing $b$. In summary, the coal species having high value of $a$ has a high leaching fraction at initial stage of leaching time (eluted early), while coal species having high value of $b$ has a fast leaching rate.
For the sample I which has high value for both constant $a$ and $b \quad$ (Table 2), has a highest As leaching fraction at initial stage of leaching test (eluted early) and has a fast leaching rate. On the other hand, the sample $\mathrm{L}$ which has lowest value of $a$ and high value of $b$, has the lowest leaching fraction at initial stage of leaching test and the leaching rate increased with increasing time. Also, the samples $\mathrm{G}$ and $\mathrm{J}$, which are coal types with high value of $a$, can be evaluated as coal types in which arsenic is eluted much in the initial stage of the leaching test. By substituting the values of $a$ and $b$ into Eq. (2), the change in leaching fraction $\mathrm{X}$ can be calculated for each number of days.

As discussed previously, the leaching fraction of arsenic related with $\mathrm{CaO}$ content in fly ash. The relation between $\mathrm{CaO}$ content in fly ash and constant $a$ was observed in order to evaluate the correlation between $\mathrm{CaO}$ content in fly ash and leaching rate of arsenic. Fig. 7 shows the relation between $\mathrm{CaO}$ content in fly ash and constant $a$. The leaching rate of arsenic (indicated by constant $a$ value) was decreased with an increase of $\mathrm{CaO}$ content in fly ash. Therefore, the value of the rate constant $a$ can be said to be the main factor determining arsenic leaching. Arsenic

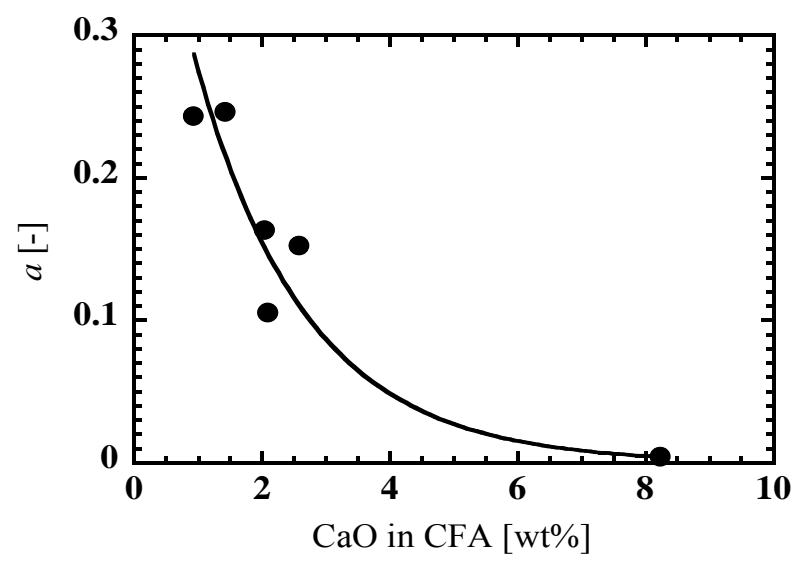

Fig. 7 Relation between $\mathrm{CaO}$ content in CFA and constant $a$ obtained by data fitting based on Eq. (2). 
leaching can be suppressed by controlling this.

In light of this, it is important to control the amount of $\mathrm{CaO}$ for arsenic leaching suppression, and it is necessary to add $\mathrm{CaO}$ content onto fly ash with an appropriate addition amount to prevent the leaching of arsenic.

\section{Conclusion}

The leaching characteristics of arsenic from CFA were investigated for six different CFA samples that were collected from a large scale power plant in Japan. The arsenic leaching fractions were examined through experimental and calculation, the influence of time was investigated and the leaching rate was evaluated. The specific conclusions were described as follows:

The leaching fractions of arsenic were low levels below $15 \%$. It was affected by $\mathrm{CaO}$ content in CFA.

The leaching fractions of arsenic from equilibrium calculation were $100 \%$ for all fly ash samples, and this result is significantly differed with experimental result. As the time through equilibrium calculation has been assumed as infinite time, this observation indicates that leaching of arsenic is time-dependent.

Long-term leaching test shows that whole amount of arsenic was eluted at equilibrium. Most of arsenic in CFA was eluted at 120 days.

For the quantitative evaluation of leaching characteristics, the leaching rate equation was defined using modified kinetic model of first-order reactions involving two variables: the constants $a$ and $b$. The constants $a$ and $b$ are estimated by data fitting to the equation.

The coal species having high value of $a$ has a high leaching fraction at initial stage of leaching time (eluted early) and has a slow speed, while coal species having high value of $b$ has a fast leaching rate.

It is found that the constant $a$ has a good relationship with $\mathrm{CaO}$ content in CFAs, in which the constant $a$ (indicated leaching rate of arsenic) was decreased with an increase of $\mathrm{CaO}$ content in fly ash. Therefore, the value of the rate constant $a$ can be said to be the main factor determining arsenic leaching. Arsenic leaching can be suppressed by controlling this.

In light of this, it is important to control the amount of $\mathrm{CaO}$ for arsenic leaching suppression by adding $\mathrm{CaO}$ content onto fly ash with an appropriate addition amount to prevent the leaching of arsenic, and it is hoped that more extended study will be made to develop the arsenic leaching suppression method for CFA.

\section{References}

[1] Frandsen, F., Dam-Johansen, K., and Rasmussen, P. 1994. "Trace Elements from Combustion and Gasification of Coal-An Equilibrium Approach." Prog. Energy Combust. Sci. 20: 115-38.

[2] Keefer, R. F. 1993. "Coal Ashes-Industrial Wastes or Benefecial By-products?" In Trace Elements in Coal and Coal Combustion Residues, edited by Keefer, R. F., and Sajwan, K. S. Florida: Lewis Publishers.

[3] Swaine, D. J., and Goodarzi, F., eds. 1995. Environmental Aspects of Trace Elements in Coal. Dordrecht: Kluwer.

[4] IPCS (International Program on Chemical Safety) and WHO (World Health Organization). 2001. "Environmental Health Criteria for Arsenic and Arsenic Compounds." Geneva.

[5] Otero-Rey, J. R., Mato-Fernandez, M. J., Moreda-Pineiro, J., Alonso-Rodriguez, E., Muniategui-Lorenzo, S., Lopez-Mahia, P., and Prada-Rodriguez, D. 2005. "Influence of Several Experimental Parameters on Arsenic and Selenium Leaching from Coal Fly Ash Samples." Anal. Chim. Acta 531 (2): 299-305.

[6] Baba, A., and Kaya, A. 2004. "Leaching Characteristics of Fly Ash from Thermal Power Plants of Soma and Tuncbilek, Turkey." Environ. Monit. Assess. 9 (1-3): 171-81.

[7] Brunori, C., Balzamo, S., and Morabito, R. 1999. "Comparison between Different Leaching/Extraction Tests for the Evaluation of Metal Release from Fly Ash." Int. J. Environ. Anal. Chem. 75 (1-2): 19-31.

[8] Jankowski, J., Ward, C. R., French, D., and Groves, S. 2005. "Mobility of Trace Elements from Selected Australian Fly Ashes and Its Potential Impact on Aquatic Ecosystems." Fuel 85 (2): 243-56.

[9] Iwashita, A., Sakaguchi, Y., Nakajima, T., Takanashi, H., Ohki, A., and Kambara, S. 2005. "Leaching Characteristics of Boron and Selenium for Various Coal Fly Ashes." Fuel 84 (5): 479-85. 
[10] EPRI (Electric Power Research Institute). 2006. "Characterization of Field Leachates at Coal Combustion Product Management Sites: Arsenic, Selenium, Chromium, and Mercury Speciation." Palo Alto, CA, 1012578.

[11] Xu, Y., Nakajima, T., and Ohki, A. 2001. "Leaching of Arsenic from Coal Fly Ashes 1. Leaching Behavior of Arsenic and Mechanism Study." Toxicol. Environ. Chem. 81 (1-2): 55-68.

[12] Wang, T., Wang, J., Tang, Y., Shi, H., and Ladwig, K. 2009. "Leaching Characteristics of Arsenic and Selenium from Coal Fly Ash: Role of Calcium.” Energy \& Fuel 23: 2959-66.

[13] Jiao, F., Ninomiya, Y., Zhang, L., Yamada, N., Sato, A., and Dong, Z. 2013. "Effect of Coal Blending on the Leaching Characteristics of Arsenic in Fly Ash from Fluidized Bed Coal Combustion.” Fuel Processing Technology 106: 769-75.

[14] Grisafe, D. A., Angino, E. E., and Smith, S. M. 1988. "Leaching Characteristics of a High Calcium Fly Ash as a Function of $\mathrm{Ph}$ : A Potential Source of Selenium Toxicity." Appl. Geochem. 3: 601-8.
[15] Yudovich, Y. E., and Ketris, M. P. 2005. "Arsenic in Coal: A Review.” Int. J. Coal. Geol. 61: 141-96.

[16] Zielinski, R. A., Foster, A. L., Meeker, G. P., and Brownfield, I. K. 2007. "Mode of Occurrence of Arsenic in Feed Coal and Its Derivative Fly Ash, Black Warrior Basin, Alabama." Fuel 8: 560-72.

[17] Jankowski, J., Ward, C. R., French, D., and Groves, S. 2004. "Leachability of Heavy Metals from Selected Australian Fly Ashes and Its Implications for Groundwater Contamination." In Proceedings of the 21st Annual International Pittsburgh Coal Conference on Coal-Energy and the Environment, 23.

[18] Jankowski, J., Ward, C. R., French, D., and Groves, S. 2004. "Trace Element Mobility from Selected Australian Fly Ashes." In Proceedings of the 21st Annual International Pittsburgh Coal Conference on Coal-energy and the Environment, 13-7.

[19] Ugurlu, A. 2004. "Leaching Characteristics of Fly Ash." Environ. Geol. 46: 5-6.

[20] Levenspiel, O. 1999. Chemical Reaction Engineering. 3rd ed. New York: John Wiley \& Sons. 